\title{
Adesão ao tratamento clínico no transtorno de personalidade borderline
}

\author{
Patrícia Helena Vaz Tanesi \\ Latife Yazigi \\ Maria Luiza de Mattos Fiore \\ José Cássio do Nascimento Pitta \\ Universidade Federal de São Paulo
}

\begin{abstract}
Resumo
Adesão é um comportamento complexo, envolve desde pequenas recusas ao tratamento até o uso inadequado dos serviços de saúde e abandono do tratamento. O presente trabalho é um estudo qualitativo com seis pacientes com transtorno de personalidade borderline sobre adesão ao tratamento, utilizando análise qualitativa em entrevista aberta, questionário psicossocial, classificação diagnóstica pela SCID I e II e acompanhamento clínico. Os resultados mostraram que impulsividade, manipulação, dissociação afetiva, tentativa de suicídio, tendência à regressão e agressividade dificultaram ou impossibilitaram a adesão ao tratamento. Concluímos que os casos que abandonaram o tratamento colocaram a equipe em uma situação de impotência e apelo para estratégias sociais como forma de manejo da situação. É levantada a hipótese de que familiares saudáveis podem ser importantes para a adesão ao tratamento. Nos casos que não abandonaram o acompanhamento, a não-adesão se manifestou como ataques ao vínculo, ataques a melhora, e agressividade voltada à equipe e à instituição.
\end{abstract}

Palavras-chave: adesão ao tratamento; transtorno de personalidade borderline; impulsividade; agressividade

\begin{abstract}
Compliance in the treatment of borderline personality disorders. Compliance is a complex behavior, ranging from minor instances of treatment refusal to the inappropriate use of health services or even treatment abandonment. The study comprises a qualitative analysis of six patients with borderline personality disorder submitted to an open interview, a psychosocial questionnaire, a diagnostic classification through SCDI I and II and a clinical follow-up. Six behaviors made treatment compliance either difficult or impossible: impulsivity, manipulation, affective dissociation, attempted suicide, tendency to regression, and aggression. The participants who abandoned the treatment made the health team impotent, requiring social strategies to manage the situation. We hypothesized that healthy families are of great importance for compliance to treatment. For the cases in which treatment was not abandoned, non-compliance was manifested as attacks against the bonds and against the improvement, and aggression towards the health team and the institution.
\end{abstract}

Keywords: compliance to treatment; borderline personality disorder; impulsivity; aggression

$\mathrm{O}$ Manual Diagnóstico e Estatístico de Transtornos Mentais (DSM-IV-TR, 2002) classifica adesão ao tratamento como uma das condições primordiais na atenção clínica. Adesão é definida como um comportamento complexo que inclui não só as características do paciente, mas também do clínico e das estratégias de tratamento utilizadas. Dunbar (1980), em um estudo de revisão sobre os determinantes da adesão, mostra que fatores relacionados à estratégia e ao regime de tratamento são os mais importantes. Blackwell (2000) afirma que, quando a autoridade médica e a autonomia do paciente são discutidas, temas como respeito às crenças, às atitudes e às opiniões tornamse os focos do estudo.

Esta questão torna-se mais complexa ainda quando se entra no campo dos transtornos de personalidade, em particular do paciente borderline. O DSM-IV-TR (2002) caracteriza o transtorno de personalidade borderline como um padrão global de instabilidade dos relacionamentos interpessoais, da auto-imagem e dos afetos, e acentuada impulsividade que começa no início da idade adulta e está presente em uma variedade de contextos.

Em geral, a não-adesão a um tratamento envolve muitos 
comportamentos: relutância em procurar ajuda, rejeição a procedimentos como exames laboratoriais, consultas e sessões irregulares, interrupções prematuras no acompanhamento, nãocumprimento das orientações, uso de dose inadequada e de medicações não recomendadas (Blackwell, 2000).

As razões conscientes mais comuns referidas pelos pacientes para não aderirem ao tratamento e freqüentarem as sessões de psicoterapia são frustração com o tratamento, falta de suporte social e dificuldades logísticas em comparecer às consultas (Gunderson, 1989).

Stone (2006), em um estudo de revisão sobre tratamentos psicológicos, salienta a existência de três linhas psicoterapêuticas maiores para o manejo do transtorno de personalidade borderline: psicodinâmica, cognitivo-comportamental e suportiva. $\mathrm{O}$ autor observa que todas elas, apesar de diferirem em suas características específicas, buscam melhorar os sintomas e as dificuldades desses pacientes. Reconhece que os terapeutas devem lidar com seis problemas sérios no início do processo: suicídio e auto-mutilações, ameaças de interrupção precoce do tratamento, depressão, abuso de substâncias, manifestações de ansiedade e pânico, e dissociação. Também refere outras questões que surgem depois de superados esses problemas: raiva injustificada, mordacidade, manipulação, reivindicações, ciúmes, pensamento do tipo tudo ou nada, atitudes extremas como idealização e desvalorização, e traços masoquistas.

Quanto ao efeito das intervenções psicológicas em pacientes com transtorno de personalidade borderline, Binks (2000), em uma revisão sistemática, conclui que os problemas encontrados em pacientes com transtorno de personalidade borderline podem ser aliviados com tratamentos que envolvem conversa ou comportamentais, mas todas as terapias ainda estão na fase experimental. Os estudos são poucos e limitados para inspirar uma completa confiança em seus resultados. Os achados requerem replicação em estudos maiores no "mundo real".

O presente estudo visa contribuir para a compreensão de fatores que interferem na adesão ao tratamento em pacientes com transtorno de personalidade borderline, identificando comportamentos que podem estar relacionados a esta dificuldade.

\section{Método}

\section{Participantes}

Foram recrutados onze pacientes com a ajuda de profissionais da área da saúde mental de diferentes serviços de uma instituição pública universitária: pronto-socorro, hospital-dia, enfermaria e ambulatório. Pediu-se a estes profissionais que encaminhassem para o estudo pacientes com diagnóstico de transtorno de personalidade de difícil manejo.

Todos os pacientes assinaram termo de consentimento livre e esclarecido aprovado pela comissão de ética desta instituição, dentro dos padrões exigidos pela Declaração de Helsink.

Dos 11 pacientes entrevistados, três foram excluídos do estudo por apresentarem respectivamente personalidade antisocial, retardo mental e transtorno bipolar episódio misto com ausência de transtorno de personalidade. Dois outros pacientes não completaram as avaliações. Assim, dos seis pacientes, todos do sexo feminino, que iniciaram o tratamento, três abandonaram e três permanecem até hoje vinculados à instituição, em tratamento.

Na Tabela 1 encontramos a descrição dos participantes.

Tabela 1

Identificação das pacientes

\begin{tabular}{lccc}
\hline Nome & Idade & Estado Civil & Escolaridade \\
\hline Alba & 26 & Solteira & Superior incompleto \\
Kelly & 25 & Solteira & Superior incompleto \\
Mara & 26 & Solteira & Superior incompleto \\
Doralice & 30 & Solteira & Superior incompleto \\
Lúcia & 21 & Solteira & Ensino médio completo \\
Íris & 41 & Solteira & Superior incompleto \\
\hline
\end{tabular}

\section{Instrumentos e procedimentos}

Os pacientes foram submetidos a uma entrevista livre quando lhes foi pedido para contarem sua história de vida e para responderem a um questionário psicossocial que serviu de estímulo para que relatassem a história de sua família. Esses encontros foram gravados e posteriormente transcritos. O objetivo foi avaliar as diferenças nas opiniões, nas atitudes, nos sistemas de valores e crenças subjacentes da pessoa, uma vez que o comportamento de não-adesão pode decorrer dessas características (Rodrigues, 1978).

Em seguida, os pacientes foram re-avaliados por meio das entrevistas clínicas estruturadas: SCID-I (First, Gibbon, Spitzer, \& Williams, 1995), versão clínica para o DSM-IV traduzida e adaptada para o português (Del-Ben, Rodrigues, \& Zuardi, 1996); e SCID-II (Sptizer, Williams, Gibbon, \& First, 1990), versão para DSM-III-R traduzida e adaptada para o português (Del-Ben et al, 1996). O objetivo destes instrumentos foi a classificação diagnóstica.

Os pacientes do estudo passaram então a ser acompanhados em atendimentos psicoterápico e psiquiátrico. A psicoterapia teve uma abordagem de orientação psicanalítica, a freqüência das sessões variou de duas a três vezes por semana. $\mathrm{O}$ atendimento psiquiátrico buscou abrandar a intensidade dos sintomas do transtorno borderline e tratar suas comorbidades em consultas que variaram de uma vez por semana a uma vez por mês.

\section{Análise dos dados}

Foi feito estudo de um grupo de casos sistematizados por meio dos instrumentos e procedimentos descritos acima. Esse tipo de delineamento qualitativo é particularmente útil na prática clínica, como salienta Fonagy (2005). No entanto, o autor afirma que, apesar de demonstrar o refinamento da técnica clínica e a inovação do tratamento, os achados não podem ser generalizados para toda a população clínica. Marshall (2006), por sua vez, assinala a vantagem que esse método tem de levar o leitor ao próprio local onde o fenômeno ocorre de forma viva e com uma riqueza de detalhes que não se observa em outros formatos.

Dos dados colhidos foram feitas leituras e releituras até que apareceram construtos que pudessem sugerir o porquê das 
dificuldades da adesão em cada caso. Patton (2002) descreve esse processo como análise indutiva em que os temas e as categorias emergem do próprio material, ou seja, não são estabelecidos previamente.

Os construtos foram posteriormente validados através da interação entre os demais pesquisadores que não participaram diretamente da coleta do material com os pacientes. Foram levantadas considerações a favor ou contra determinado construto que depois foram avalizadas pela equipe da pesquisa. Turato (2003) chama essa etapa da pesquisa clínico-qualitativa de processo de validação externa, ou interpessoal.

Para não revelar a identidade dos participantes foi dado um nome fictício e retiradas informações que pudessem identificálos.

Os três participantes excluídos do estudo foram encaminhados para tratamento, um passou a ser atendido em outro serviço da Instituição e os outros dois foram para unidade básica de saúde de seu bairro.

\section{Resultados}

Nas Tabelas 2 e 3 são descritos os diagnósticos e as principais características da entrevista e questionário psicossocial.

Os construtos identificados que interferiram na adesão e a

Tabela 2

Diagnósticos de Eixo I e II

\begin{tabular}{|c|c|c|}
\hline Nome & Eixo I - DSM-IV & Eixo II - DSM-III-R \\
\hline Alba & $\begin{array}{l}\text { Transtorno depressivo maior recorrente, severo com } \\
\text { aspectos psicóticos (atual). } \\
\text { Dependência de anfetamina (atual) } \\
\text { Dependência de ansiolítico (atual) } \\
\text { Anorexia nervosa (atual) } \\
\text { Transtorno psicótico SOE (durante a vida) }\end{array}$ & $\begin{array}{l}\text { Transtorno passivo-agressivo } \\
\text { de personalidade } \\
\text { Transtorno de personalidade } \\
\text { borderline }\end{array}$ \\
\hline Kelly & $\begin{array}{l}\text { Transtorno depressivo maior, recorrente moderado } \\
\text { (atual e durante a vida). } \\
\text { Transtorno psicótico breve (atual e durante a vida) }\end{array}$ & $\begin{array}{l}\text { Transtorno paranóide de } \\
\text { personalidade } \\
\text { Transtorno de personalidade } \\
\text { borderline }\end{array}$ \\
\hline Mara & $\begin{array}{l}\text { Transtorno depressivo maior, episódio único (durante a } \\
\text { vida). } \\
\text { Transtorno obsessivo-compulsivo (atual) }\end{array}$ & $\begin{array}{l}\text { Transtorno histriônico de } \\
\text { personalidade } \\
\text { Transtorno de personalidade } \\
\text { borderline }\end{array}$ \\
\hline Doralice & $\begin{array}{l}\text { Transtorno depressivo maior recorrente severo com } \\
\text { aspectos psicóticos (atual e durante a vida) } \\
\text { Transtorno dismórfico corporal (atual) } \\
\text { Bulimia nervosa (atual e durante a vida) }\end{array}$ & $\begin{array}{l}\text { Transtorno de personalidade } \\
\text { borderline }\end{array}$ \\
\hline Lúcia & $\begin{array}{l}\text { Transtorno psicótico SOE (durante a vida) } \\
\text { Abuso de ansiolítico (durante a vida) } \\
\text { Transtorno dissociativo NE (atual e durante a vida) } \\
\text { Anorexia nervosa (durante a vida) } \\
\text { Bulimia nervosa (atual) }\end{array}$ & $\begin{array}{l}\text { Transtorno paranóide de } \\
\text { personalidade } \\
\text { Transtorno histriônico de } \\
\text { personalidade } \\
\text { Transtorno de personalidade } \\
\text { borderline }\end{array}$ \\
\hline Íris & $\begin{array}{l}\text { Transtorno depressivo maior recorrente em remissão } \\
\text { completa (durante a vida) } \\
\text { Transtorno de pânico com agorafobia (durante a vida) }\end{array}$ & $\begin{array}{l}\text { Transtorno autodestrutivo de } \\
\text { personalidade } \\
\text { Transtorno paranóide de } \\
\text { personalidade } \\
\text { Transtorno de personalidade } \\
\text { borderline }\end{array}$ \\
\hline
\end{tabular}


Tabela 3

Dados da entrevista e do questionário psicossocial

\begin{tabular}{|c|c|}
\hline Nome & Características das entrevistas e questionários \\
\hline Alba & $\begin{array}{l}\text { Fala intensa, aderente; discurso pobre e monotemático. } \\
\text { Foco no corpo e doença, coloca-se como vítima nas relações que estabelece. } \\
\text { Família de classe popular com poucos interesses. }\end{array}$ \\
\hline Kelly & $\begin{array}{l}\text { Fala prolixa; discurso persecutório, pobreza ideativa e emocional. } \\
\text { Foco auto-referente } \\
\text { Família de classe média com poucos interesses }\end{array}$ \\
\hline Mara & $\begin{array}{l}\text { Fala econômica, sintética; discurso conciso, adequado e preciso. } \\
\text { Foco em eventos traumáticos de sua história em sua história } \\
\text { Família de classe média com poucos interesses }\end{array}$ \\
\hline Doralice & $\begin{array}{l}\text { Fala confusa; discurso sem encadeamento. } \\
\text { Foco na doença e no corpo } \\
\text { Família de classe média com alguns interesses }\end{array}$ \\
\hline Lúcia & $\begin{array}{l}\text { Fala desorganizada, intensa e aderente; discurso e concepções empobrecidos. } \\
\text { Foco na doença e no corpo } \\
\text { Família de classe popular com alguns interesses }\end{array}$ \\
\hline Íris & $\begin{array}{l}\text { Fala prolixa; discurso com momentos de perda do fio condutor, difícil compreensão e muito } \\
\text { detalhado. } \\
\text { Foco na lembrança do passado e suas minúcias. } \\
\text { Família de classe média com maior diversidade de interesses }\end{array}$ \\
\hline
\end{tabular}

descrição resumida dos casos são os que seguem.

\section{Impulsividade}

A história de Alba é marcada por gestos impulsivos, tentativas de suicídio, auto-agressões, prostituição para pagar dívidas e cirurgias plásticas. Também fazem parte de sua história clínica transtorno alimentar e abuso de anfetaminas.

$\mathrm{Na}$ avaliação psiquiátrica foi possível observar a hostilidade, o humor instável, as idéias prevalentes de auto-referência e a rejeição a fazer o acompanhamento psiquiátrico neste serviço.

$\mathrm{O}$ processo psicoterápico caracterizou-se pelas inúmeras faltas e pela ambivalência em se vincular ao terapeuta. Uma fala sua mostra a gravidade de sua impulsividade: "Estes impulsos suicidas vêm à minha cabeça, e assim como estou falando com você neste minuto, não sei o que posso fazer no instante seguinte." Seu acompanhamento durou três meses e depois por mais de um mês, por meio de contatos telefônicos quando sempre dizia que viria, mas deixava o terapeuta esperando.

A família de Alba em nenhum momento se mostrou disponível a participar do seu tratamento.

A psiquiatra da unidade básica de saúde onde Alba faz seu acompanhamento nos informou que ela continua a ir às consultas, mas se nega a fazer psicoterapia.

\section{Manipulações}

A história de Kelly é marcada pela baixa tolerância a frustrações desde a infância, o que resultava em explosões de raiva e manipulações.
O acompanhamento psiquiátrico, que durou seis meses, caracterizou-se pelas inúmeras faltas às consultas e uso indiscreto e abusivo de chamadas celulares à psiquiatra. Como não obtinha a atenção que desejava, faltava indiscriminadamente às sessões, à terapia e às consultas.

No processo psicoterápico, marcado por inúmeras faltas, chamaram a atenção os sentimentos de amor e ódio que Kelly tinha por seus pais. Após seis meses, interrompeu o tratamento. Foram várias as tentativas de contatá-la por telefone para saber se retornaria, mas foi desligada do estudo quando ficou claro que estava sendo acompanhada em outro serviço. Após alguns meses, quando sua vaga já estava ocupada por outro paciente, retornou com a família exigindo ser atendida. Queria receitas e atestados médicos. Não foi possível à equipe romper o círculo: "Não dão a atenção que quero, então eu falto". Foi re-encaminhada para o serviço onde estava sendo acompanhada. A manipulação de seus atendimentos comprometeu sua adesão ao tratamento.

A família de Kelly teve uma participação ambivalente nos atendimentos. Sua mãe fazia acompanhamento por depressão em outro serviço e seu pai, embora necessitasse de atendimento psicoterápico, não aceitou a proposta.

\section{Dissociação afetiva}

A historia de Mara é marcada por dois traumas: a perda da mãe aos dois anos de idade em um acidente em que o pai fica paraplégico e o abuso sexual pelo avô paterno dos sete aos 14 anos. Aos 25 anos inicia as tentativas de suicídio, as internações psiquiátricas e o uso de medicações, sem aderir a qualquer tra- 
tamento proposto.

Neste serviço ficou em acompanhamento psiquiátrico por três meses quando fazia uso irregular das medicações e faltava muito. Mara não tinha nenhuma crítica em relação à gravidade de seus traumas e de seu comportamento. Seu afeto era predominantemente dissociado e atribuía suas faltas a não estar precisando de atendimento.

Em relação ao processo psicoterápico, era patente seu grau de dissociação após uma tentativa de suicídio em que ficou hospitalizada 45 dias. A terapeuta a descreve como apresentando grande vivacidade e desenvoltura, nenhuma angústia ou interesse em pesquisar os motivos que a levaram a tomar uma atitude tão violenta.

A participação do pai de Mara nos atendimentos se caracterizou por atitudes invasivas, inadequadas e desrespeitosas em relação à filha e à equipe. Entretanto, sua avó paterna presente em um dos atendimentos mostrou-se cuidadosa e preocupada.

Não foi possível dar continuidade aos atendimentos, pois Mara abandonou seu tratamento.

\section{Tentativas de Suicídio e Auto-Agressões}

A história de Doralice é marcada por inúmeras internações psiquiátricas decorrentes principalmente de auto-agressões e tentativas de suicídio.

$\mathrm{O}$ atendimento psiquiátrico foi orientado sobretudo para a contenção do seu comportamento auto-agressivo.

O processo psicoterápico foi dificultado por seu estado quase que constante de sedação decorrente da quantidade necessária de medicações e seu atendimento foi muitas vezes interrompido por causa das internações.

Sua família não lhe dava suporte. A mãe tinha o hábito de alterar reiteradamente as prescrições médicas, comportava-se agressivamente com a equipe (discutia com os residentes do hospital-dia e do pronto-socorro) ameaçando interromper o tratamento da filha. Ao invés de se aliar à equipe para melhor cuidar da filha, dificultava muito o atendimento.

\section{Tendência a regressão}

Chamaram a atenção na história psiquiátrica de Lúcia os encaminhamentos para ambulatórios cada vez mais especializados. A unidade básica de saúde a encaminhou para a instituição onde passou pelo ambulatório de transtornos alimentares, depois hospital-dia e finalmente para atendimento de transtornos de personalidade. Estes encaminhamentos decorrem da falta de recursos dos diferentes locais para lidarem com os comportamentos regressivos de Lucia, como gritos e chutes durante os atendimentos, tentativas desorganizadas de agredir a psiquiatra e o psicoterapeuta, tentativas de pular pela janela durante os atendimentos, atirar e quebrar objetos. Estes comportamentos interrompiam os atendimentos ambulatoriais, pois Lucia precisava ser muitas vezes sedada e por vezes contida.

$\mathrm{O}$ processo psicoterápico caracterizou-se, no início, pelo acolhimento e contenção do ódio e da raiva. Assim, eram intervenções como abraçar Lucia quando tentava pular pela janela, ir de mãos dadas com ela ao pronto-socorro para tomar ansiolítico. Esses manejos ajudaram Lúcia a diminuir tais comportamentos, apesar de ainda hoje ameaçarem seu tratamento.
A mãe de Lúcia sempre se mostrou muito participativa, com boa capacidade de continência e seguindo as orientações terapêuticas. É assídua às consultas e aceitou fazer psicoterapia.

\section{Agressividade}

A história de Íris é marcada por ser filha de um relacionamento extraconjugal do pai que a leva para casa para ser criada pela esposa. Só tomou conhecimento desse fato aos 30 anos por uma psicóloga. Sua historia psiquiátrica começou aos 24 anos, quando interrompeu a faculdade após um crime passional que envolveu um casal de estudantes. Íris passou a fazer acompanhamentos psiquiátrico e psicoterápico, evoluiu com piora e comportamentos auto-agressivos que culminaram em duas internações psiquiátricas e no diagnóstico de transtorno de personalidade borderline.

No acompanhamento psiquiátrico teve dificuldade para aderir às recomendações medicamentosas e faltava às consultas. Apresentou sérias explosões de raiva tanto no pronto-socorro como no hospital-dia e nos atendimentos psicoterápico e psiquiátrico quando contrariada, quando impostos limites ou quando se sentia perseguida.

O processo psicoterápico caracterizou-se por um clima assustador. Temos os seguintes relatos de seu terapeuta:

"Pequenos contratempos provocam em Íris graves acessos de fúria, deixando aterrorizados a mim e aos que se encontram nas imediações [...] não preciso dizer das profundas repercussões que essas crises me causaram, medo, vontade de desistir, dor de estar 'casado psicoterapicamente' com alguém tão violento."

Íris só conta com a mãe que é muito idosa, seu pai é falecido.

\section{Discussão}

O objetivo deste artigo é contribuir para a compreensão dos fatores que interferem na adesão ao tratamento de pacientes com transtorno de personalidade borderline, identificando comportamentos que podem estar relacionados a essa dificuldade. Como é utilizado um método qualitativo de estudo de um grupo de casos, não é possível generalizar os resultados. $\mathrm{O}$ aspecto positivo do estudo é a possibilidade da análise do fenômeno no próprio local onde ele ocorre de forma viva e com riqueza de detalhes (Fonagy, 2005; Marshall, 2006). Desta forma é observado que, mesmo após a definição de uma estrutura de tratamento estável, do estabelecimento dos limites e da tolerância às condutas hostis e destrutivas, ou seja, mesmo depois da aplicação dos princípios recomendados para o tratamento deste transtorno (Kernberg, 1991), surgem dificuldades que complicam ou inviabilizam o tratamento e que parecem estar relacionadas à adesão ao tratamento.

O presente estudo sugere que os comportamentos de nãoadesão envolvem não somente o abandono propriamente dito do tratamento, como vemos nos casos de Alba, Kelly e Mara, mas também os ataques ao vínculo vistos no caso de Lúcia, os ataques à melhora no caso de Doralice e a agressividade voltada à equipe e à instituição no caso de Íris.

Nos pacientes que abandonaram o tratamento, foram identificados os construtos da impulsividade, da manipulação e da 
dissociação afetiva.

A impulsividade foi o que pareceu impedir Alba de se manter em psicoterapia. É provável que suas vontades e impulsos a fazer coisas no horário de suas sessões a impediram de vir ao tratamento. A impulsividade é um sintoma de difícil conceituação e, conseqüentemente, de difícil mensuração. Muitas escalas e medidas foram desenvolvidas para sua avaliação, entretanto uma observação comum na literatura é de que essas medidas não têm uma intercorrelação satisfatória (Barratt, 1985; Corulla, 1987; Luengo, Carrillo-de-la-Peña, \& Otero, 1991; Malle \& Neubauer, 1991; Parker, Bagby, \& Webster, 1993). Além do mais, o consenso sobre o que constitui a impulsividade é reduzido (Parker et al., 1993). A baixa correlação entre as diferentes medidas de impulsividade reflete a diversidade das considerações teóricas sobre este construto (Parker \& Bagby, 1997). Neste artigo, o termo impulsividade é entendido como relacionado aos problemas de regulação da esfera volitiva, de dificuldades na inibição de emoções, de atos e de pensamentos.

A impulsividade do paciente borderline parece estar relacionada à desesperança e à sensação de vazio de sentido na vida. A crença de estar sem apoio e a falta de esperança no futuro levam ao desespero, aos atos impulsivos e a situações de risco. O comportamento impulsivo, comum praticamente a todos os pacientes, tem duas possibilidades de controle: (a) internamente, por meio de mecanismos de defesa como repressão, supressão, reação formativa e estratégias cognitivas como abstenção; (b) externamente, por meio do controle ambiental. Alguns clínicos buscam somente o controle interno, baseados na premissa de que o controle verdadeiro é o autocontrole (Coles, 1997).

Entretanto, enquanto esses pacientes não desenvolverem condições de controle interno, o externo se torna necessário, seja por meio de medicações ou estratégias sociais. Dois tipos significativos de estratégias são encontrados na literatura: as intervenções familiares, sendo importante a identificação do papel das relações familiares na patogênese e manutenção da sintomatologia do paciente (Gabbard, 1998); e a construção de uma rede social de apoio através de um interventor social (Correia, 2003). No caso de Alba não foi possível intervenção familiar pela sua falta de disponibilidade. Um interventor social parece que pouco poderia fazer por Alba, pois ela não tolerava a presença de outras pessoas em seus espaços, conversando com familiares, colegas e amigos.

A manipulação identificada em Kelly reflete a falta de limites do paciente borderline que fará de tudo para que sua vontade seja soberana. Não consegue perceber o outro, mas somente suas próprias necessidades. O outro não tem existência própria e sua função é servi-lo. Acredita ser sempre espoliado e os outros serem seus eternos devedores. Estas atitudes e crenças se relacionam às alterações cognitivas. (Beck \& Freeman, 1993; Skodol, 2002). Não era possível trabalhar com a paciente as questões relacionadas a sua adesão devido as suas faltas. Em relação à família, não foi possível intervir em sua ambivalência quanto ao tratamento. Também aqui é provável que um interventor social pouco pudesse fazer devido a intensidade das atitudes manipulativas e da ambivalência da família.

A dissociação afetiva de Mara a impediu de ter crítica sobre a gravidade de sua condição e de sua necessidade de tratamento.
Esse comportamento é comum nos pacientes borderlines. Além de impedir a adesão, pode facilitar as tentativas de suicídio. Parece que este estado afetivo levou Mara a desenvolver o que Kernberg (1991) chama de uma defesa hipomaníaca contra a depressão, levando-a a uma convicção abrupta de que o tratamento não era mais necessário. As estratégias sociais conhecidas teriam pouca influência sobre ela neste estado.

Nos pacientes que permaneceram em tratamento, foram caracterizados como fatores que interferiram na adesão: a repetição das tentativas de suicídio, a regressão e a agressividade.

A repetição das tentativas de suicídio e auto-agressões foram identificadas como forma de não-adesão no caso de Doralice. É possível que fossem um ataque ao trabalho feito e a sua melhora, já que todo o progresso era anulado com as repetições crônicas destes gestos. Estas ameaças crônicas podem estar envolvidas com questões narcisistas. Podem ser uma revanche pela humilhação sentida ou punição por frustrações sentidas como intoleráveis e injustas. Podem competir com o terapeuta de modo que um sucesso por parte do terapeuta pode ser sentido como uma derrota para eles. Desta forma, não se estabelece uma verdadeira aliança terapêutica, a equipe fica sem condições de ajudar este paciente, o que constitui uma ameaça ao tratamento. A vida social de Doralice se restringia ao hospital-dia e às visitas a familiares. Foi feito um trabalho com sua família, porém os poucos recursos intelectuais da mãe limitaram o alcance deste trabalho.

Um dos aspectos importantes, mas desconsiderado nos critérios para transtorno de personalidade borderline, é a tendência à regressão (Skodol, 2002). O que leva o paciente a não aderir ao tratamento quando frustrado na satisfação de seus desejos. No caso de Lúcia, observamos as dificuldades dos locais de atendimento em lidarem com este comportamento e a tendência que tiveram de encaminhar para outros locais e desligar do acompanhamento. Esta paciente não percebia que provocava sua exclusão dos locais de atendimento com este comportamento e acabava por sentir-se rejeitada. Ao rejeitar os atendimentos com seu comportamento regressivo acabava rejeitada. Este modo de agir é conhecido na abordagem psicanalítica como identificação projetiva. Acreditamos que Lúcia não abandonou os tratamentos (sendo sempre encaminhada para outros serviços), dada a presença assídua e participativa de sua mãe na possibilidade de tratar sua filha.

As explosões de agressividade de Íris sugerem uma manifestação de ódio intensa, uma transferência negativa maciça em relação à equipe e à instituição. Kernberg (1991) descreve nos pacientes borderline um tipo de transferência que inclui esforços para se livrarem de aspectos odiosos das suas representações internalizadas de si mesmos e dos seus objetos por meio da projeção destes aspectos sobre membros da equipe. Os pacientes então buscam o controle do outro temido e odiado, percebido agora como ameaçador, incompetente, desonesto, negligente ou não-confiável. O autor considera este comportamento como uma ameaça de abandonar o tratamento. Bateman e Fonagy (2004) inferem que as reações agressivas e as explosões violentas podem ser vistas como aspectos da impulsividade que variam em relação à severidade do comportamento sendo considerada como uma atitude defensiva para proteger o self de uma ameaça à sua estabilidade. Isto ocorre porque a intenção do outro não 
é adequadamente entendida ou por seu próprio estado mental estar em alerta. Os autores também vêem estas reações ligadas a sentimentos de irritação, raiva e ódio, podendo decorrer de menor controle dos impulsos, de idéias persecutórias ou de necessidade de atenção. Os afetos e emoções são descarregados de forma violenta e acarretam, muitas vezes, risco de vida, prejuízo material e grave perturbação nas relações interpessoais e no tratamento. Foram observadas estas perturbações na equipe nos atendimentos de Íris. Existia um risco ao se atender Íris, o que limitava o tratamento. Vemos a sua dificuldade de adesão nesta transferência negativa que estabelece com a instituição.

Em todos os casos descritos é observada falha no processo primário de vinculação conforme descrito por Bateman e Fonagy (2004), o que sugere que o borderline não teve condições de aprender que sua mente não espelha concretamente o mundo, mas antes representa e interpreta o mundo, capacidade de "mentalizar" que garante um sentido estável ao self. Quando essa capacidade está comprometida, a relação terapêutica fica marcada por repetições de ruptura dos tratamentos. No estudo, observamos que estas rupturas podem ser o abandono propriamente dito do tratamento ou os ataques a seu progresso.

Os transtornos de personalidade têm grande impacto social e médico. São freqüentes os divórcios, os problemas no trabalho, a violência e as co-morbidades clínicas como depressão, suicídio, dependência de drogas e impulsividade (Bland, Stebelsky, Orn, \& Newman, 1988; Johnson et al. 2000; McCraine \& Kahan, 1986; Seiverwright, Tyrer, \& Johnson, 1998; Skodol et al. 1999). Estes achados mostram sua importância na saúde pública. A adesão é essencial para possibilitar uma terapêutica efetiva que resulte numa diminuição deste impacto.

\section{Conclusão}

Impulsividade, manipulações, dissociação afetiva, tentativas de suicídio acompanhadas de auto-agressões crônicas, tendência à regressão e agressividade foram identificadas como fatores interferindo na adesão ao tratamento dos casos acompanhados.

Os casos que abandonaram o tratamento parecem ter colocado a equipe em uma situação de impotência e apelo para estratégias sociais como forma de manejo da situação.

A estratégia social utilizada no estudo foi a intervenção familiar. É levantada a hipótese de que familiares saudáveis podem ser muito importantes para a adesão ao tratamento. A mãe de Lúcia, presente em quase todos os atendimentos, assídua e participativa, mostrou-se determinante na possibilidade de tratar sua filha e de ela não ter abandonado o acompanhamento.

Nos casos de não abandono do acompanhamento, a nãoadesão apareceu como ataques ao vínculo, ataques à melhora, e agressividade voltada para a equipe e para a instituição.

Estudos do processo terapêutico a longo prazo de pacientes com transtorno de personalidade borderline são necessários para melhor entendimento e tratamento de sua dinâmica.

\section{Agradecimentos}

Agradecemos à Fundação de Amparo à Pesquisa do Estado de São Paulo, FAPESP, pelo apoio.

\section{Referências}

American Psychiatric Association. (Org). (2002). Manual Diagnóstico e Estatístico de Transtornos Mentais. Texto Revisado (p. 690). São Paulo: Artmed.

Barratt, E. S. (1985). Impulsiveness subtraits: arousal and information processing. In J. T. Spence \& C. E. Itard (Orgs.), Motivation, emotion and personality (pp. 137-146). Amsterdam: Elsevier/North-Holland.

Bateman, A., \& Fonagy, P. (2004). Psychotherapy for Borderline Personality Disorder: mentalization-based treatment (pp. 234 e 55-109). Londres: Oxford University Press.

Beck, A. T., \& Freeman, A. (1993). Terapia cognitiva dos transtornos de personalidade (pp. 141, 151 e 152). Porto Alegre: Artes Médicas.

Binks, C. A., Fenton, M., McCarthy, L., Lee, T., Adams C. E., \& Duggan, C. (2006). Psychological therapies for people with borderline personality disorder. Cochrane Database System Review, 1, CD005652.

Blackwell, B. (2000). Additional conditions that may be a focus of clinical attention. In B. J. Sadock \& V. A. Sadock (Orgs.), Comprehensive textbook of Psychiatry (pp. 1893-1898). Philadelphia: Lippincott Williams \& Wilkins.

Bland, R. C., Stebelsky, G., Orn, H., \& Newman, S. C. (1988). Psychiatric disorders and unemployment in Edmonton. Acta Psychiatrica Scandinavica, 77(suppl. 338), 72-80.

Coles, E. M. (1997). Impulsivity in major mental disorders. In C. D. Webster, \& M. A. Jackson (Orgs.), Impulsivity: theory, assessment, and treatment (pp. 180-194). Nova York: Guilford.

Corrêa, P. O. (2003). Programa de abordagem interdisciplinar no tratamento do transtorno de personalidade borderline. Revista de Psiquiatria do Rio Grande do Sul, 25, 42-51.

Corulla, W. J. (1987). A psychometric investigation of the Sensation Seeking Scale Form V and its relationship to the 1.7 Impulsiveness Questionnaire. Personality and Individual Differences, 8, 651-658.

Del-Ben, C. M., Rodrigues, C. R. C., \& Zuardi, A. W. (1996). Reliability of the Portuguese version of the structured clinical interview for DSM-III-R in a Brazilian sample of psychiatric outpatients. Brazilian Journal of Medical Research, 29(12), 1675-1682.

Dunbar, J. (1980). Adhering to medical advice: a review. International Journal of Mental Health, 9, 70-87.

First, M. B., Gibbon, M., Spitzer, R. L., \& Williams, J. B. W. (1995). User's guide for the Structured Clinical Interview for the DSM-IV-Axis I Disorders. Nova York: State Psychiatric Institute.

Fonagy P., \& Roth, A. (2005). What works for whom (pp. 16-42). Londres: Guilford.

Gabbard, G. O. (1998). Psiquiatria psicodinâmica (pp. 100-110). Porto Alegre: Artes Médicas.

Gunderson, J. C., Prank, A. F., Romnningstam, E. F., Wachter, S., Lynch, V. J., \& Wolf, P. B. (1989). Early discontinuance of borderline patients from psychotherapy. Journal of Nervous and Mental Diseases, 177, 38-42.

Johnson, J. G., Cohen, P., Smailes, E., Kasen, S., Oldham, J. M., Skodol, A. E. et al. (2000).0 Adolescent personality disorders associated with violence and criminal behavior during adolescence and early adulthood. American Journal of Psychiatry, 157, 1406-1412.

Kernberg, O. F., Seltzer, M. A., Koenigsberg, H. W., Carr, A. C., \& Appelbaum, A. H. (1991). Psicoterapia psicodinamica de pacientes borderline (pp. 34-57 e 164-170). Porto Alegre: Artmed.

Luengo, M. A., Carrillo-de-la-Peña, M. T., \& Otero, J. M. (1991). The components of impulsiveness: a comparison of the 1.7 Impulsiveness Questionnaire and the Barratt Impulsiveness Scale. Personality and Individual Differences, 12, 657-667.

Malle, B. F., \& Neubauer, A. C. (1991). Impulsivity, reflection, and questionnaire response latencies: no evidence for a broad impulsivity trait. Personality and Individual Differences, 12, 865-871. 
Marshall, C., \& Rossman, G. B. (2006). Designing qualitative research (pp. 5193). Thousand Oaks, California: Sage.

McCraine, E. W., \& Kahan, J. (1986). Personality and multiple divorces: a prospective study. Journal of Nervous and Mental Disease, 174, 161-164.

Parker, J. D. A., Bagby, R. M., \& Webster, C. D. (1993). Domains of the impulsivity construct: a factor analytic investigation. Personality and Individual Differences, 15, 267-274.

Parker, J. D. A., \& Bagby, R. M. (1997). Impulsivity in adults: a critical review of measurement approaches. In C. D. Webster, \& M. A. Jackson (Orgs.), Impulsivity: theory, assessment, and treatment (pp. 142- 155). Nova York: Guilford.

Patton, M. Q. (2002). Qualitative research and evaluation methods (pp. 448-458) Thousand Oaks, California: Sage.

Rodrigues, A. M. (1978). Operário, operária: estudo exploratório sobre o operariado industrial da Grande São Paulo (pp. 31-41). São Paulo: Símbolo.

Seiverwright, H., Tyrer, P., \& Johnson, T. (1998). Prediction of outcome in neurotic disorder: a 5- year prospective study. Psychological Medicine,
28, 1149-1157.

Skodol, A. E., Stout, R. L., McGlashan, T. H., Grilo, C. M., Gunderson, J. G, Shea, M. T. et al. (1999). Co-occurrence of mood and personality disorders: a report from the Collaborative Longitudinal Personality Disorders Study (CLPS). Depression and Anxiety, 10, 175-182.

Skodol, A. E., Gunderson, J. G., Pfohl, B., Widiger, T. A., Livesley, W. J., \& Siever, L. J. (2002). The borderline diagnosis I: psychopathology, comorbidity, and personality structure. Biological Psychiatry, 51(12), 936-950.

Sptizer, R. L., Williams, J. R., Gibbon, M., \& First, M. B. (1990). Structured clinical interview for DSM-III-R - patient edition (SCID-II, version 1.0). Washington, DC: American Psychiatric Press.

Stone, M. H. (2006). Management of borderline personality disorder: a review of psychotherapeutic approaches. Word Psychiatry, 5, 15-20.

Turato, E. R. (2003). Tratado da metodologia da pesquisa clínico-qualitativa: construção teórico-epistemológica, discussão comparada e aplicação nas áreas de saúde e humanas (pp. 391-392). Petrópolis, RJ: Vozes.

Patrícia Helena Vaz Tanesi, médica psiquiatra, é supervisora clínica no Ambulatório Didático do Departamento de Psiquiatria, Universidade Federal de São Paulo. Endereço para correspondência: Universidade Federal de São Paulo; Departamento de Psiquiatria; Rua Botucatu, 740; São Paulo, SP. Telefone: (11) 5579-2828. E-mail: ptanesi@uol.com.br

Latife Yazigi, doutora em psicologia pela Universidade de São Paulo, é professora titular no Departamento de Psiquiatria da Universidade Federal de São Paulo. E-mail: latife.yazigi@pq.cnpq.br Maria Luiza de Mattos Fiore, doutora em Psiquiatria e Psicologia Médica pela Universidade Federal de São Paulo, é médica na mesma instituição.

José Cássio do Nascimento Pitta, mestre em Psiquiatria e Psicologia Médica pela Universidade Federal de São Paulo, é professor assistente na mesma instituição. 